\title{
The Nomenclature of the Veins of the Lower Limbs, Based on their Planar Anatomy and Fascial Relationships
}

\author{
A. Caggiati \\ Department of Anatomy, University "La Sapienza”, Rome Italy.
}

All past editions of the official Terminologia Anatomica (TA) were extremely concise regarding with the veins of the lower limb (1), especially if the great number of vessels described in the clinical literature is considered. For example, the list of perforating veins and that of saphenous collaterals were inadequate and some important deep veins were not mentioned.

This is why, time after time, many clinicians introduced new names to indicate "new" veins, resulting in a terminological chaos (more than one name for the same vein and/or the same name for more than one vein).

A revision and extension of venous terminology was needed in order to facilitate effective exchange of information and to avoid inappropriate treatment of venous diseases (2). An "ad hoc" International Interdisciplinary Committee (International Union of Phlebology and International Federation of Anatomical Association) elaborated a revision of the venous nomenclature (3) which has been already accepted by the Federative International Committee on Anatomical Terminology (FICAT) and will be included in the next edition of the official "Terminologia Anatomica".

In this article, main terminological changes and extensions are reported, taking into account the improvements in anatomical knowledge furnished by modern techniques of "virtual" dissection (Duplex, spiral CT, MR).

\section{Three planes of veins}

The veins of the lower limbs are traditionally designated according with their relationships with the Deep Fascia (DF). This separates the limb in two venous planes : the epifascial plane, with the superficial veins, and the $s u b$ fascial one, with the deep veins. A third group includes those veins which cross the DF (Perforating Veins, PV).

This traditional classification considers the subcutaneous tissue an amorphous layer of fat. On the contrary, the subcutaneous tissue is supported by a connective skeleton which strands, in correspondence of the saphenous veins (SVs), interlace to form a continuous membrane. This membrane is officially called "saphenous fascia" (SF) $(3,4,5)$.

The SF overlies the SVs to join the underlying DF at the sides of the vessels. The two fasciae $(\mathrm{SF}+\mathrm{DF})$ delimit a narrow fatty space which is officially named "saphenous compartment" (SC) $(4,5)$ because it contains, besides SVs, only related nerves and arteries.

The roots of SVs (medial marginal vein, superficial venous arch of the foot and lateral marginal vein), and the thigh extension of the Small Saphenous Vein are enclosed in a similar space. As a consequence, the SC extends uninterrupted from the groin down to the dorsal foot and, on the posterior face of the limbs, from the lateral malleolus to the gluteal fold.

All other superficial veins (saphenous tributaries, accessories and collaterals) course out of the SC, in a more superficial plane of the subcutaneous tissue, close to the dermis.

According with their fascial relationships, the veins of the lower limbs are to be divided in three groups (table 1), one for each of the three planes delimited by the DF and SF: Subfascial Veins (Deep Vv.), Interfascial Veins (SVs), Epifascial Veins (Superficial Vv.).

Table 1

\begin{tabular}{|c|c|}
\hline Old classification & New classification \\
\hline \multirow{2}{*}{ SUPERFICIAL VEINS } & EPIFASCIAL VEINS \\
\cline { 2 - 2 } & saphenous fascia \\
\cline { 2 - 2 } & INTERFASCIAL VEINS \\
\hline muscular fascia & muscular fascia \\
\hline DEEP VEINS & DEEP VEINS \\
\hline
\end{tabular}

\section{Deep Veins}

With regard to the deep veins, the Committee proposed :

1. to avoid the misleading term "Superficial Femoral Vein", because it is not a superficial vein. The Femoral Vein origins from the popliteal vein and continues into the Common Femoral Vein after having received the Deep Femoral Vein.

2. To avoid the misleading term "Perforating Veins" to indicate the roots of the Deep Femoral Vein. These have been designated Deep Femoral Communicating Veins. The term "Perforating" is to be used exclusively for those veins which connect superficial with deep veins by piercing the DF. 
3. To designate the Sural veins (6) as : the Soleal Veins, the Medial Gastrocnemius Veins, the Lateral Gastrocnemius Veins, and, finally, the Intergemellar Vein.

4. To introduce the term Sciatic Vein to indicate the vein accompanying the sciatic nerve and which continues into the inferior gluteal vein.

\section{Interfascial veins :}

With regard to the interfascial veins, the Committee recommended that :

1) The Saphenous Veins must be indicated only with the term "Great" and "Small" in order to respect their official name (Vena Saphena Magna and Parva) and to avoid confusions between acronyms (respectively, GSV and SSV).

2) The cranial prolongation of the SSV along the posterior thigh must be indicated with the term Upward (or Thigh) Extension of the SSV ( $\left.{ }^{1}\right)$.

\section{Epifascial (superficial) veins}

The epifascial venous plane is composed by a net of interconnecting veins which are extremely variable in number, size, path and connection. However, an order can be found in this variability. In fact, if most of epifascial veins are short, thin, unnamed and unnameable, a few of them are quite constant and show distinct anatomical markers. These are designated in longitudinal and oblique ones.

Longitudinal epifascial veins are parallel to the SVs and richly connected with them. For these reasons, they are designated as "Accessories" of the relative Saphena and discriminated on the basis of their topography.

The Accessories of the GSV which course in a more anterior position are called Anterior Accessory of the GSV $\left({ }^{2}\right)$.

The Accessories of the GSV which course in a more posterior position are called Posterior Accessory of the GSV ( $\left.{ }^{3}\right)$.

Finally, those running along the same path but more superficially are called Superficial Accessory of the GSV.

Besides SVs Accessories, the Lateral Venous Plexus (also called vein of Albanese) is to be considered in the group of longitudinal epifascial veins.

Due to their course, oblique epifascial veins play the hemodynamic role of communicating main longitudinal veins (SVs or their accessories). The flow in them is directed cranially toward the GSV.

The oblique veins of the leg are called Intersaphenous Veins.

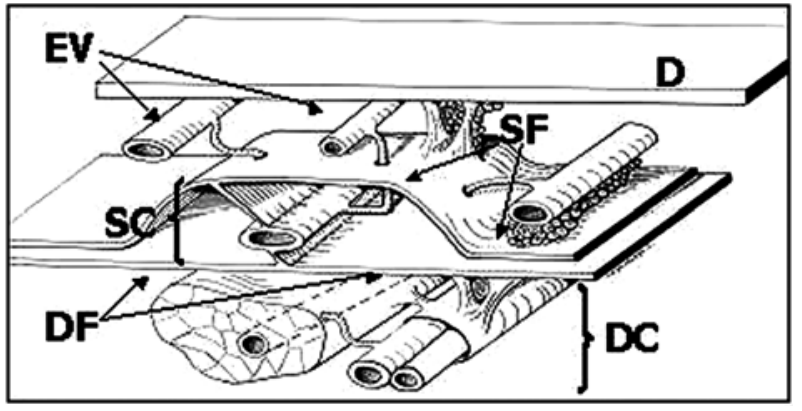

Fig. 1

Schematic drawing of the fascial and venous arrangement of the lower limbs. D : Dermis; EV : Epifascial Veins; SF : Saphenous Fascia ; SC : Saphenous Compartment ; DF : Deep Fascia ; DV : Deep Veins.

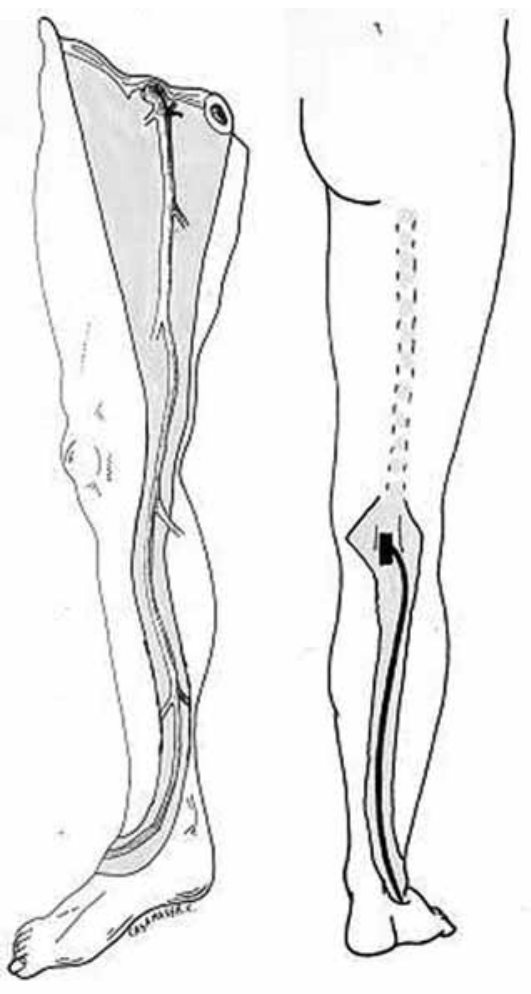

Fig. 2

Extension of the Compartment of the GSV (on the left) and of the SSV (on the right). Note that the two compartments are connected on the dorsum of the foot (along the marginal veins and the superficial venous arch).

(1) The term "Vein of Giacomini" is misleading and must be substituted with "Giacomini's anastomosis. It is an anastomosis between the SSV and the GSV. The "Giacomini's anastomosis" courses along the Thigh Extension of the SSV (that is an interfascial vein) and the Posterior Thigh Circumflex Vein (an epifascial vein).

(2) The upper portion of the AAGSV courses, like the GSV, under a fascia similar to the SF. The AAGSV can be discriminated from the GSV because it courses just above the femoral vessels.

(3) The PAGSV of the leg corresponds to the well known "Posterior Arch Vein". 

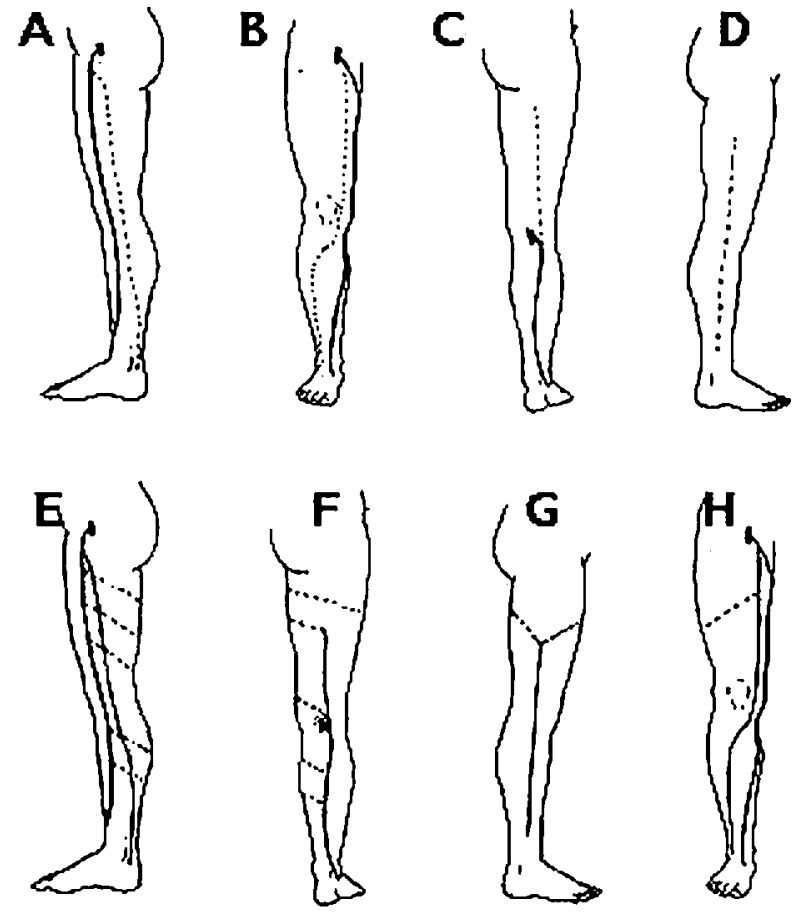

Fig. 3

A) The approximate path of the Posterior Accessories of the GSV. B) The approximate path of the Anterior Accessories of the GSV. C) The Thigh extension of the SSV. D) The approximate path of the lateral plexus. E and F) At the leg, intersaphenous veins. At the thigh, the Posterior Thigh Circumflex Veins. $\mathrm{G}$ and $\mathrm{H}$ ) The Lateral Venous Plexus may be drained by the Posterior or Anterior Thigh Circumflex Veins.

In the thigh, oblique veins are designated "Circumflex Veins" due to their path. In the anterior thigh, the oblique veins which connect the Lateral Venous Plexus with the GSV are called Anterior Thigh Circumflex Vein(s) (ATCV). In the posterior thigh, the Posterior Thigh Circumflex Vein(s) (PTCV) originate from the SSV, from the Lateral Plexus or from reticular veins of the posterior thigh, to drain into the GSV or its Posterior Accessory.

\section{Perforating veins}

The term Perforating Vein (PV) or Perforator is the only acceptable to indicate the veins crossing the DF to connect superficial with deep vein. PV are numerous and very variable in arrangement, connection, size and distribution (7). PV were designated according with their topography and were grouped as in table 2 and in Figure 5. Despite the apparent complexity, groups and names are consistent with their relevant anatomy.

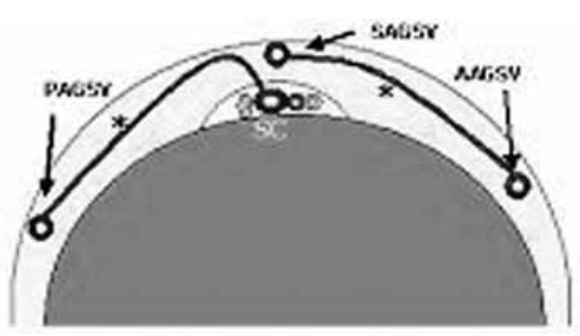

Fig. 4

The path of oblique veins, which connect main longitudinal veins. SAGSV, AAGSV and PAGSV: Superficial, Anterior and Posterior Accessory Great Saphenous Veins. SC: Saphenous Compartment. *: Oblique communicating veins.

Table 2

Perforating veins

\begin{tabular}{|c|c|c|}
\hline Main groups & Sub-groups & Ref. \\
\hline \multirow{4}{*}{ FoOt Perforators } & Dorsal PV or INTERCAPITUlar VeINS & 1 \\
\hline & Medial PV & 2 \\
\hline & LATERAL PV & 3 \\
\hline & Plantar PV & 4 \\
\hline \multirow{3}{*}{ AnKle Perforators } & Medial PV & 5 \\
\hline & ANTERIOR PV & 6 \\
\hline & LATERAL PV & 7 \\
\hline \multirow{4}{*}{ Leg Perforators } & $\begin{array}{l}\text { MEdial PV } \\
\text { - PARATIBIAL PV } \\
\text { - POSTERIOR TIBIAL PV }\end{array}$ & $\begin{array}{l}8 \\
9\end{array}$ \\
\hline & ANTERIOR PV & 10 \\
\hline & LATERAL PV & 11 \\
\hline & $\begin{array}{l}\text { Posterior PV } \\
\text { - MEdiAL GASTROCNEMIUS PV } \\
\text { - LATERAL GASTROCNEMIUS PV } \\
\text { - INTERGEMELLAR PV } \\
\text { - PARA-ACHILLEAN PV }\end{array}$ & $\begin{array}{l}12 \\
13 \\
14 \\
15\end{array}$ \\
\hline \multirow{5}{*}{ Knee Perforators } & MEdial PV & 16 \\
\hline & SuPRAPATELLAR PV & 17 \\
\hline & LATERAL PV & 18 \\
\hline & INFRAPATELLAR PV & 19 \\
\hline & PoPLitEAL FOSSA PV & 20 \\
\hline \multirow{5}{*}{ THIGH PERFORATORS } & $\begin{array}{l}\text { MEDIAL THIGH PV } \\
\quad-\text { PV OF THE FEMORAL CANAL } \\
\text { - INGUINAL PV }\end{array}$ & $\begin{array}{l}21 \\
22\end{array}$ \\
\hline & ANTERIOR THIGH PV & 23 \\
\hline & LATERAL THIGH PV & 24 \\
\hline & $\begin{array}{l}\text { POSTERIOR THIGH PV } \\
- \text { POSTERO-MEDIAL } \\
\text { - SCIATIC PV } \\
\text { - POSTEROLATERAL }\end{array}$ & $\begin{array}{l}25 \\
26 \\
27\end{array}$ \\
\hline & PUDENDAL PV & 28 \\
\hline \multirow{3}{*}{ GLUTEAL PERFORATORS } & SUPERIOR GLUTEAL PV & 29 \\
\hline & MID GLUTEAL PV & 30 \\
\hline & LOWER GLUTEAL PV & 31 \\
\hline
\end{tabular}



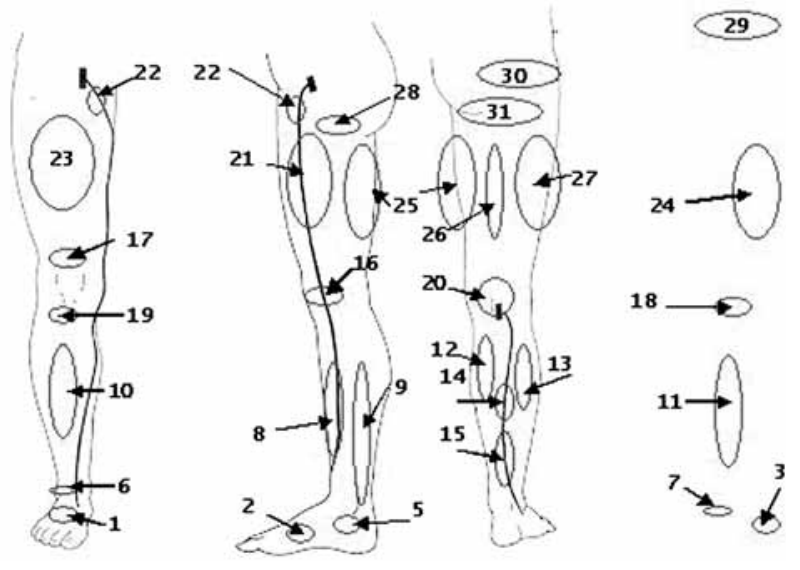

Fig. 5

The location of the main groups of PV. For legends, see Table 2.

\section{Eponyms and synonyms}

Eponyms cannot be included in the Official Terminology. However, eponym or synonym can be used in the clinical practice only if clearly corresponded to an official names. For this reason, the Committee indicated the correspondence between more used eponyms or synonyms with the official names of that veins.

\section{Table 3}

\begin{tabular}{|l|l|}
\hline Posterior Arch Vein (Leonardo's Vein) & Leg portion of the PAGSV \\
Giacomini's anastomosis & Thigh SSV + PTCV \\
Cockett PV & Posterior tibial PV \\
Boyd PV & Paratibial PV \\
Dodd PV & PV of the femoral \\
& (Hunterian) canal \\
Bassi PV & ParaAchillean PV \\
May PV & Intergemellar PV \\
Hach PV & Posterolateral thigh PV \\
Gillot PV & Medial Gastrocnemius PV \\
\hline
\end{tabular}

\section{Conclusions}

Anatomy of the venous system forms the basis of clinical phlebology and is crucial to the correct evaluation and appropriate treatment of venous disorders. Deficiency in the nomenclature of the veins of the lower limbs, however, became obvious as knowledge accumulated about their physiology and pathophysiology.

The official names of some veins have been changed and previously unnamed veins have received names relevant to their anatomy and clinical significance according to the guidelines of the FICAT. Some of the terminology recommendations are innovative, but they have been adopted in most of the recent phlebological papers and meeting.

\section{References}

1. Federative International Committee for Anatomical Terminology. Terminologia Anatomica. George Thieme Verlag, Stuttgart, 1998.

2. Bundens W. P., Bergan J. J., Halasz N. A., Murray J., Drehobl M. The superficial femoral vein : a potentially lethal misnomer. JAMA, 1995, 274 : 1296-1298.

3. Caggiati A., Bergan J. J., Gloviczki P., Jantet G., WendellSmith C. P., Partsch H. Nomenclature of the veins of the lower limbs: an international interdisciplinary consensus statement. $J$ Vasc Surg, 2002, 36 : 416-22.

4. Caggiati A. Fascial relationships of the long saphenous vein. Circulation, 1999, 100 : 2547-2549.

5. CAgGiati A. Fascial relationships of the short saphenous vein. $J$ Vasc Surg, 2001, 34 : 241-246.

6. Van der Stricht J., Staelens J. Veines musculaires du mollet. Phlébologie, 1994, 47 : 135-143.

7. May R., Partsch H., Staubesand J. Perforating Veins. Urban and Schwarzenberg, München, 1980.

A. Caggiati, M.D., Ph.D.

Department of Anatomy,

University "La Sapienza",

Via Borelli 50,

00153, Rome Italy,

E-mail : alberto.caggiati@uniroma1.it. 